Journal of Mathematics and Informatics

Vol. 9, 2017, 29-34

ISSN: 2349-0632 (P), 2349-0640 (online)

Published 27 October 2017

www.researchmathsci.org

DOI: http://dx.doi.org/10.22457/jmi.v9a4

Journal of

Mathematics and

Informatics

\title{
Common Fixed Point Theorem for Weakly Compatible Mappings in Metric Space
}

\author{
V.Naga Raju
}

Department of Mathematics, University College of Engineering (Autonomous)

Osmania University, Hyderabad-500007(Telangana), India

Email:viswanag2007@gmail.com

Received 16 October 2017; accepted 26 October 2017

Abstract. In this paper we prove a common fixed point theorem for pairs of weakly compatible mappings in a metric space which generalizes the existing result.

Keywords: Fixed point, self maps, weakly compatible mappings, associated sequence.

AMS Mathematics Classification (2010): 54H25, 47H10

\section{Introduction}

In 1976, Jungck proved some common fixed point theorems for commuting maps which generalize the Banach contraction principle. Further this result was generalized and extended in various ways by several authors. On the other hand Sessa [5] introduced the concept of weak commutativity and proved a common fixed point theorem for weakly commuting maps. In 1986, G.Jungck[1] introduced the concept of compatible maps which is more general than that of weakly commuting maps. Afterwards Jungck and Rhoades [4] introduced the notion of weakly compatible and proved that compatible maps are weakly compatible but not conversely.

The purpose of this paper is to prove a common fixed point theorem for four self maps in metric space using weaker conditions such as weakly compatible mappings and associated sequence related to four self maps.

\section{Definitions and Preliminaries}

Definition 2.1. [1] Two self maps $S$ and $T$ of a metric space $(X, d)$ are said to be compatible mappings if $\lim _{n \rightarrow \infty} d\left(S T x_{n}, T S x_{n}\right)=0$ whenever $\left\{x_{n}\right\}$ is a sequence in $\mathrm{X}$ such that $\lim _{n \rightarrow \infty} S x_{n}=\lim _{n \rightarrow \infty} T x_{n}=t$ for some $t \in X$.

Definition 2.2. [4] Two self maps $S$ and $T$ of a metric space (X,d) are said to be weakly compatible if they commute at their coincidence point. i.e., if $S u=T u$ for some $u \in X$ then $S T u=T S u$. 


\section{V.Naga Raju}

Definition 2.3. [9,11] Suppose $\mathrm{P}, \mathrm{Q}, \mathrm{S}$ and $\mathrm{T}$ are self maps of a metric space $(X, d)$ such that $S(X) \subset Q(X)$ and $T(X) \subset P(X)$. Now for any arbitrary $x_{0} \in X$, we have $S x_{0} \in S(X) \subset Q(X)$ so that there is a $x_{1} \in X$ such that $S x_{0}=Q x_{1}$ and for this $x_{1}$, there is a point $x_{2} \in \mathrm{X}$ such that $T x_{1}=P x_{2}$ and so on. Repeating this process to obtain a sequence $\left\{y_{n}\right\}$ in X such that $y_{2 n}=P x_{2 n}=T x_{2 n-1}$ and $y_{2 n+1}=Q x_{2 n+1}=S x_{2 n}$ for $n \geq 0$.

We shall call this sequence an associated sequence of $x_{0}$ relative to the four self maps $\mathrm{P}, \mathrm{Q}, \mathrm{S}$ and $\mathrm{T}$.

Lemma 2.4. Let $\mathrm{P}, \mathrm{Q}, \mathrm{S}$ and $\mathrm{T}$ be self mappings of a metric space $(X, d)$ satisfying $S(X) \subset Q(X)$ and $T(X) \subset P(X)$

and $d(S x, T y) \leq\left[\alpha+\beta \frac{d(\mathrm{~S} x, \mathrm{P} x)}{1+d(P x, Q y)}\right] d(\mathrm{Ty}, Q y)$

for all $\mathrm{x}, \mathrm{y}$ in $\mathrm{X}$, where $\alpha, \beta \geq 0, \alpha+\beta<1$.

Further if $\mathrm{X}$ is complete,then for any $\mathrm{x}_{0} \in \mathrm{X}$ and for any of its associated sequence $\left\{y_{n}\right\}=\left\{S x_{0}, T x_{1}, S x_{2}, T x_{3}, \ldots . . S x_{2 n}, T x_{2 n+1}, \ldots ..\right\}$ relative to four self maps, converges to some point in $X$.

Proof: From (2.3) and (2.4.2), we have

$$
\begin{aligned}
& d\left(y_{2 n}, y_{2 n+1}\right)= d\left(T x_{2 n-1}, S x_{2 n}\right) \\
&= d\left(S x_{2 n}, T x_{2 n-1}\right) \\
& \leq {\left[\alpha+\beta \frac{d\left(\mathrm{~S} x_{2 n}, \mathrm{P} x_{2 n}\right)}{1+d\left(P x_{2 n}, Q x_{2 n-1}\right)}\right] d\left(\mathrm{Tx}_{2 n-1}, Q x_{2 n-1}\right) } \\
&= {\left[\alpha+\beta \frac{d\left(\mathrm{y}_{2 n+1}, \mathrm{y}_{2 n}\right)}{1+d\left(\mathrm{y}_{2 n}, \mathrm{y}_{2 n-1}\right)}\right] d\left(\mathrm{y}_{2 n}, \mathrm{y}_{2 n-1}\right) } \\
& \leq \alpha d\left(\mathrm{y}_{2 n}, \mathrm{y}_{2 n-1}\right)+\beta d\left(\mathrm{y}_{2 n+1}, \mathrm{y}_{2 n}\right) \text { implies } \\
&(1-\beta) d\left(y_{2 n}, y_{2 n+1}\right) \leq \alpha d\left(y_{2 n-1}, y_{2 n}\right) \text { so that } \\
& d\left(y_{2 n}, y_{2 n+1}\right) \leq \frac{\alpha}{(1-\beta)} d\left(y_{2 n-1}, y_{2 n}\right)=\mathrm{h} d\left(y_{2 n-1}, y_{2 n}\right), \text { where } h=\frac{\alpha}{1-\beta} .
\end{aligned}
$$

That is, $d\left(y_{2 n}, y_{2 n+1}\right) \leq h d\left(y_{2 n-1}, y_{2 n}\right)$.

Similarly, we can prove that $d\left(y_{2 n+1}, y_{2 n+2}\right) \leq h d\left(y_{2 n}, y_{2 n+1}\right)$.

Hence, from (2.6.3) and (2.6.4), we get

$d\left(y_{n}, y_{n+1}\right) \leq h d\left(y_{n-1}, y_{n}\right) \leq h^{2} d\left(y_{n-2}, y_{n-1}\right) \leq \ldots \ldots . \leq h^{n} d\left(y_{0}, y_{1}\right)$.

Now, for any positive integer $\mathrm{p}$ we have 
Common Fixed Point Theorem for Weakly Compatible Mappings in Metric Space

$$
\begin{aligned}
d\left(y_{n}, y_{n+p}\right) & \leq d\left(y_{n}, y_{n+1}\right)+d\left(y_{n+1}, y_{n+2}\right)+\ldots \ldots . .+d\left(y_{n+p-1}, y_{n+p}\right) \\
& \leq h^{n} d\left(y_{0}, y_{1}\right)+h^{n+1} d\left(y_{0}, y_{1}\right)+\ldots \ldots . .+h^{n+p-1} d\left(y_{0}, y_{1}\right) \\
& =\left(h^{n}+h^{n+1}+\ldots \ldots \ldots+h^{n+p-1}\right) d\left(y_{0}, y_{1}\right) \\
& =h^{n}\left(1+h+h^{2}+\ldots \ldots .+h^{p-1}\right) d\left(y_{0}, y_{1}\right) \\
& <\frac{h^{n}}{1-h} d\left(y_{0}, y_{1}\right) \rightarrow 0 \text { as } \mathrm{n} \rightarrow \infty, \text { since } \mathrm{h}<1 .
\end{aligned}
$$

Thus the sequence $\left\{y_{n}\right\}$ is a Cauchy sequence in $X$. Since $X$ is complete, the sequence $\left\{y_{n}\right\}$ converges to some point $\mathrm{z}$ in $\mathrm{X}$.

Remark 2.5. The converse of the above Lemma is not true. That is, if $\mathrm{P}, \mathrm{Q}, \mathrm{S}$ and $\mathrm{T}$ are self maps of a metric space $(X, d)$ satisfying $(2.4 .1),(2.4 .2)$ and even if for any $x_{0}$ in $\mathrm{X}$ and for any of its associated sequence converges, then the metric space $(X, d)$ need not be complete.

Example 2.6. Let $X=(0,1)$ with $d(x, y)=|x-y|$ for $x, y \in X$. Define the self maps $\mathrm{S}, \mathrm{T}, \mathrm{P}$ and $\mathrm{Q}$ on $\mathrm{X}$ by

$$
\begin{aligned}
& S x=T x=\left\{\begin{array}{l}
\frac{1}{2} \text { if } 0<x \leq \frac{1}{2} \\
\frac{2}{3} \quad \text { if } \frac{1}{2}<x \leq 1
\end{array},\right. \\
& P x=Q x=\left\{\begin{array}{ll}
1-x & \text { if } 0<x \leq \frac{1}{2} \\
\frac{1}{3} & \text { if } \frac{1}{2}<x \leq 1
\end{array} .\right.
\end{aligned}
$$

Then $S(X)=T(X)=\left\{\frac{1}{2}, \frac{2}{3}\right\}$ while $P(X)=\mathrm{Q}(\mathrm{X})=\left[\frac{1}{2}, 1\right) \cup\left\{\frac{1}{3}\right\}$.

Clearly $S(X) \subset Q(X)$ and $T(X) \subset P(X)$. It is also easy to see that the sequence $S x_{0}, T x_{1}, S x_{2}, T x_{3}, \ldots . . S x_{2 n}, T x_{2 n+1}, \ldots . .$. converges to $\frac{1}{2}$. Also the inequality (2.6.2) holds for $\alpha, \beta \geq 0, \alpha+\beta<1$. Note that $(\mathrm{X}, \mathrm{d})$ is not complete.

Now we generalize the result of Sharma et al. in the following section.

\section{Main result}

Theorem 3.1. Let $\mathrm{P}, \mathrm{Q}, \mathrm{S}$ and $\mathrm{T}$ be self maps of a metric space $(X, d)$ such that

$$
\begin{aligned}
& S(X) \subset Q(X) \text { and } T(X) \subset P(X) \\
& d(S x, T y) \leq\left[\alpha+\beta \frac{d(\mathrm{~S} x, \mathrm{P} x)}{1+d(P x, Q y)}\right] d(\mathrm{Ty}, Q y)
\end{aligned}
$$




\section{V.Naga Raju}

for all $\mathrm{x}, \mathrm{y}$ in $\mathrm{X}$ where $\alpha, \beta \geq 0, \alpha+\beta<1$.

one of $S(X)$ and $T(X)$ is closed subset of $X$

and the pairs $(\mathrm{S}, \mathrm{P})$ and $(\mathrm{T}, \mathrm{Q})$ are weakly compatible

Further if there is point $x_{0} \in X$ and an associated sequence

$S x_{0}, T x_{1}, S x_{2}, T x_{3} \ldots . . S x_{2 n}, T x_{2 n+1} \ldots$ of $x_{0}$ relative to four self maps $\mathrm{P}, \mathrm{Q}, \mathrm{S}$ and $\mathrm{T}$ converges to some point $z \in X$,

then $\mathrm{z}$ is a unique common fixed point of $\mathrm{P}, \mathrm{Q}, \mathrm{S}$ and $\mathrm{T}$.

Proof: From (3.1.5), we have

$S x_{2 n} \rightarrow z$ and $T x_{2 n+1} \rightarrow z$ as $n \rightarrow \infty$.

Let $\mathrm{S}(\mathrm{X})$ be a closed subset of $\mathrm{X}$. Then $z \in S(X)$.

Now, since $\mathrm{S}(X) \subset Q(X)$, there exists a $\mathrm{u} \in X$ such that $\mathrm{z}=\mathrm{Qu}$.

So by (3.1.2), we have

$d\left(S x_{2 n}, T u\right) \leq\left[\alpha+\beta \frac{d\left(\mathrm{~S} x_{2 n}, \mathrm{P} x_{2 n}\right)}{1+d\left(P x_{2 n}, Q u\right)}\right] d(\mathrm{~T} u, Q u)$

Letting $\mathrm{n} \rightarrow \infty$, we obtain

$$
\begin{aligned}
d(z, T u) & \leq[\alpha+0] d(T u, z) \\
& =\alpha \mathrm{d}(z, T u) \leq \mathrm{d}(z, T u), \text { a contradiction since } \alpha<1 .
\end{aligned}
$$

Thus we have $\mathrm{Tu}=\mathrm{z}$.

Hence $\mathrm{Qu}=\mathrm{Tu}=\mathrm{z}$.

Since the pair $(\mathrm{T}, \mathrm{Q})$ is weakly compatible mappings, we have $\mathrm{TQu}=\mathrm{QTu}$ and so that $\mathrm{Tz}=\mathrm{Qz}$.

Again from (3.1.2), we get

$d\left(S x_{2 n}, T z\right) \leq\left[\alpha+\beta \frac{d\left(\mathrm{~S} x_{2 n}, \mathrm{P} x_{2 n}\right)}{1+d\left(P x_{2 n}, Q z\right)}\right] d(\mathrm{Tz}, Q z)$

Letting $\mathrm{n} \rightarrow \infty$ and using $\mathrm{Tz}=\mathrm{Qz}$, we obtain

$d(z, \mathrm{~T} z) \leq 0$, a contradiction .

Thus we have $\mathrm{Tz}=\mathrm{z}$. 
Common Fixed Point Theorem for Weakly Compatible Mappings in Metric Space

Since $T(X) \subset P(X)$, there exists a $\mathrm{v} \in X$ such that $\mathrm{z}=\mathrm{Pv}$.

Hence from (3.1.2), we get

$d(S v, T z) \leq\left[\alpha+\beta \frac{d(\mathrm{~S} v, \mathrm{P} v)}{1+d(P v, Q z)}\right] d(\mathrm{Tz}, Q z)$

Using $\mathrm{Tz}=\mathrm{z}$, we obtain

$d(\mathrm{~S} v, z) \leq 0$, a contradiction

Thus we have $\mathrm{Sv}=\mathrm{z}$.

Hence $\mathrm{Sv}=\mathrm{Pv}=\mathrm{z}$.

Since the pair $(\mathrm{P}, \mathrm{S})$ is weakly compatible mappings, we have $\mathrm{SPv}=\mathrm{PPv}$ and so that $\mathrm{Sz}=\mathrm{Pz}$.

Now from (3.1.2), we get

$$
\begin{aligned}
d(S z, T z)= & d(S z, z) \\
& \leq\left[\alpha+\beta \frac{d(\mathrm{Sz}, \mathrm{Pz})}{1+d(P z, Q z)}\right] d(\mathrm{z}, Q z) \\
& \leq 0, \text { a contradiction. }
\end{aligned}
$$

Thus we have $\mathrm{Sz}=\mathrm{z}$.

Therefore $S z=P z=Q z=T z=z$, showing that $z$ is a common fixed point of $\mathrm{P}, \mathrm{Q}, \mathrm{S}$ and T.

Uniqueness: Let $\mathrm{z}$ and $\mathrm{w}$ be two common fixed points of $\mathrm{P}, \mathrm{Q}, \mathrm{S}$ and $\mathrm{T}$. Then we have $z=S z=P z=Q z=T z$ and $w=S w=P w=Q w=T w$.

Using (3.1.2), we get

$d(S z, T w) \leq\left[\alpha+\beta \frac{d(\mathrm{Sz}, \mathrm{Pz})}{1+d(P z, Q w)}\right] d(\mathrm{Tw}, Q w)$ implies

$\mathrm{d}(\mathrm{z}, \mathrm{w}) \leq 0$, a contradiction.

Thus we have $d(z, w)=0$ and so that $z=w$.

Hence $\mathrm{z}$ is a unique common fixed point of $\mathrm{P}, \mathrm{Q}, \mathrm{S}$ and $\mathrm{T}$.

Remark 3.2. It is easy to verify that the self mappings $P, Q, S$ and $T$ defined in the example (2.6) satisfy all the conditions of the Theorem (3.1). It may be noted that ' $\frac{1}{2}$ ' is the unique common fixed point of $\mathrm{P}, \mathrm{Q}, \mathrm{S}$ and $\mathrm{T}$.

\section{REFERENCES}

1. G.Jungck, Compatible mappings and common fixed points, Internat. J. Math. Math. Sci., 9(1986) 771-778.

2. R.P.Pant, A Common fixed point theorem under a new condition, Indian J. of Pure and App.Math.,30(2) (1999), 147-152. 


\section{V.Naga Raju}

3. G.Jungck, Compatible mappings and common fixed points (2), Internat. J. Math. And Math. Sci., 11 (1988) 285-288.

4. G.Jungck and B.E. Rhoades, Fixed point for set valued functions without continuity, Indian J. Pure. Appl. Math, 29(3) (1998) 227-238.

5. S.Sessa, On a weak commutativity condition in a fixed point considerations, Publ. Inst Math. (Beograd), 32(46) (1982) 149-153.

6. A.K.Sharma, V.H.Badshah and V.K.Gupta, Common fixed point theorems for Compatible mappings in complete metric space using rational inequality, Inst. $J$. Adv. Tech. Engg. and Science, 2 (2014) 395-407.

7. G.Jungck, P.P.Murthy and Y.J.Cho, Compatible mappings of type (A) and common fixed points, Math. Japan, 38 (1993) 381-391.

8. M.S.Khan, H.K.Pathak and G.Reny, Compatible mappings of type (A-1) and type(A2) and common fixed points in fuzzy metric spaces, International Math. Forum, 2(11) (2007) 515-524.

9. V.Srinivas and V.Nagaraju, Common fixed point theorem on compatible mappings of type (P), Gen. Math. Notes, 21(2) (2014) 87-94.

10. H.K.Pathak and M.S.Khan, A comparison of various types of compatible maps and common fixed points, Indian J. Pure Aappl. Math, 28(4) (1997) 477-485.

11. V.Nagaraju and B.Raju, A common fixed point theorem using compatible mappings of type (A-1), Annals of Pure and Applied Mathematics, 14(2) (2017) 255-262.

12. P.Malviya, V.Gupta and V.H.Badshah, Common fixed point theorem for semi compatible pairs of reciprocal continuous maps in menger spaces, Annals of Pure and Applied Mathematics, 11(2) (2016)139-144. 